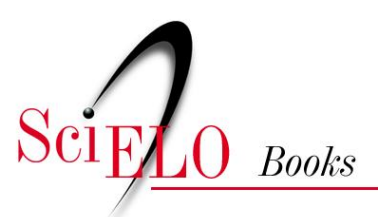

\title{
Ordem Scorpaeniformes
}

\author{
Ana Cristina Teixeira Bonecker \\ Claudia Akemi Pereira Namiki \\ Márcia Salustiano de Castro \\ Paula Nepomuceno Campos
}

\section{SciELO Books / SciELO Livros / SciELO Libros}

BONECKER, ACT., et al. Ordem Scorpaeniformes. In Catalogo dos estágios iniciais de desenvolvimento dos peixes da bacia de Campos [online]. Curitiba: Sociedade Brasileira de Zoologia, 2014, pp. 175-179. Zoologia: guias e manuais de identificação series. ISBN 978-85-98203-10-2.

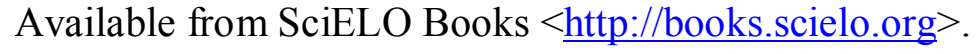

\section{(2)(1)(2)}

All the contents of this chapter, except where otherwise noted, is licensed under a Creative Commons Attribution-Non Commercial-ShareAlike 3.0 Unported.

Todo o conteúdo deste capítulo, exceto quando houver ressalva, é publicado sob a licença Creative Commons Atribuição Uso Não Comercial - Partilha nos Mesmos Termos 3.0 Não adaptada.

Todo el contenido de este capítulo, excepto donde se indique lo contrario, está bajo licencia de la licencia Creative Commons Reconocimento-NoComercial-CompartirIgual 3.0 Unported. 


\section{ORDEM SCORPAENIFORMES}

A ordem Scorpaeniformes é composta por 26 famílias com aproximadamente 1.477 espécies. São caracterizados por extensão do terceiro osso suborbital que vai desde o olho até o pré-opérculo. A cabeça é cheia de espinhos e placas ósseas.

Neste estudo a ordem Scorpaeniformes é representada pela família Scorpaenidae. 


\section{Família Scorpaenidae}

A família Scorpaenidae é marinha e ocorre em todos os mares tropicais e temperados. Compreende pelo menos 56 gêneros com aproximadamente 418 espécies. As larvas de Scorpaenidae possuem cabeça grande com muitos espinhos. Têm 1-2 espinhos operculares e 3-5 espinhos pré-operculares. São caracterizadas pela presença de um par de cristas parietais com margens serrilhadas, sustentadas por uma ou duas hastes na região terminal posterior. As larvas de Scorpaenidae podem ser separadas das larvas da família Triglidae pelas cristas parietais que nos triglídeos são sustentadas por várias hastes. A nadadeira dorsal é única, com 7-18 espinhos e 4-14 raios, e a nadadeira anal possui 2-4 espinhos e 5-14 raios.

No Brasil já foram identificadas 20 espécies nas fases de larva e adulto. Nesse estudo são contempladas as espécies Scorpaena sp. e Scorpaenodes sp. 


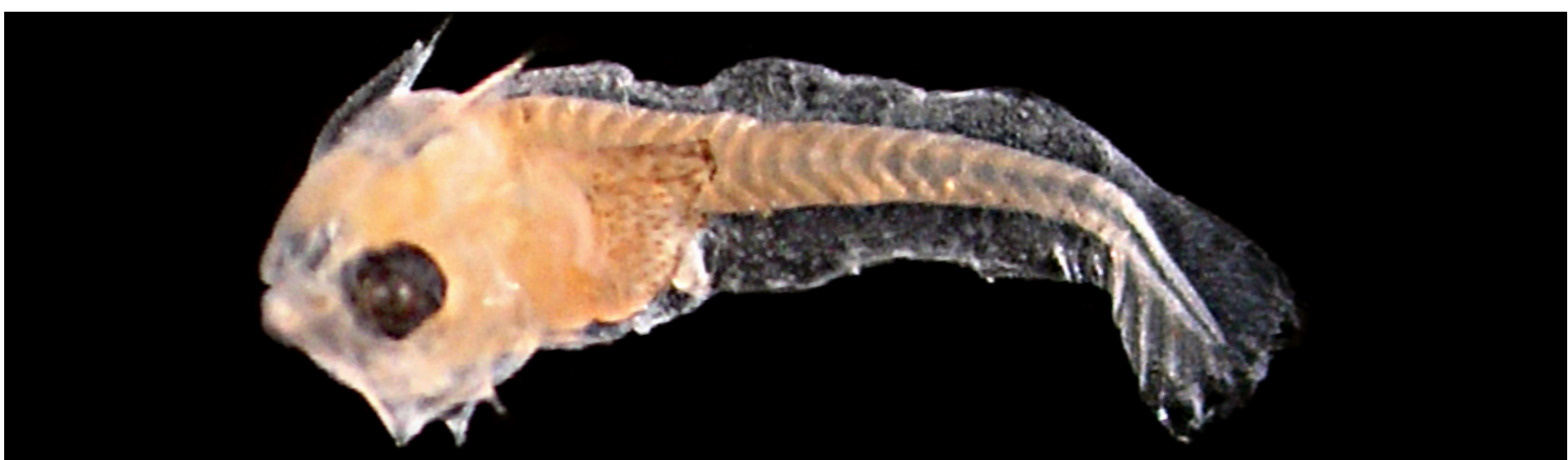

Figura 101 - A: Scorpaena sp. DZUFRJ 14030; Pré-flexão; CP 3,0 mm.

\section{Scorpaena sp.}

As larvas de Scorpaena na pré-flexão possuem uma faixa de melanóforos ao longo da linha média ventral da cauda e na superfície dorsolateral do intestino. Na flexão e pós-flexão desenvolvem um par moderadamente longo de espinhos parietais que alcançam seu maior comprimento relativo quando a formação da nadadeira caudal está completa. Presença de uma capa de melanina sobre a superfície dorso-lateral do intestino. As nadadeiras peitorais são muito pigmentadas desde a pré-flexão, moderadas em comprimento e em forma de leque, em oposição às extremamente longas em Scorpaenodes e em contraste com as aliformes de Pontinus. Possui um total de 24 miômeros. No Brasil já foram registradas onze espécies de Scorpaena.

Tamanho: pré-flexão 2,0-4,0 mm; flexão 4,5-5,5 mm; pós-flexão 6,8-8,0 mm.

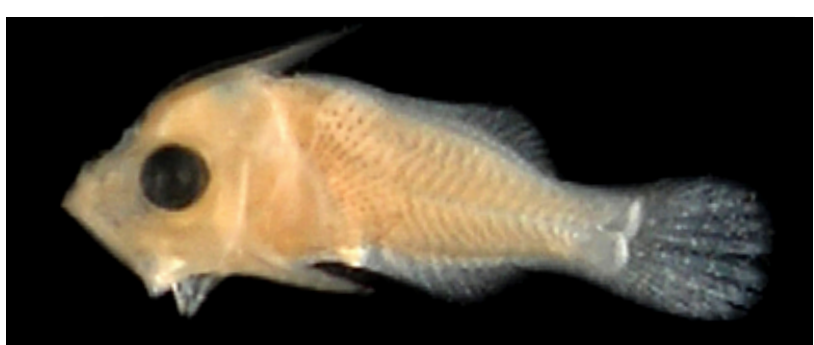

Figura 101 - B: DZUFRJ 13594; Flexão; CP 4,5 mm.

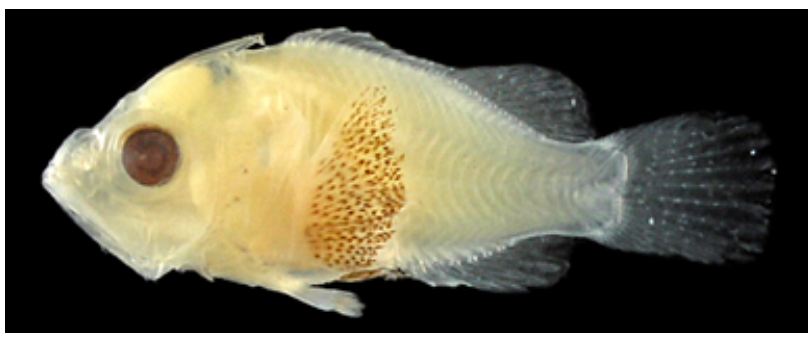

Figura 101 - C: DZUFRJ 5741; Pós-flexão; CP 6,8 mm.

Habitat: todas as espécies de Scorpaena registradas na literatura são marinhas e demersais.

\section{Georreferencimento}

\begin{tabular}{|c|c|c|c|c|c|c|c|c|}
\hline DZUFRJ & Latitude (S) & Longitude (W) & Data & $\begin{array}{l}\text { Tipo de } \\
\text { arrasto }\end{array}$ & $\begin{array}{c}\text { Profundidade } \\
\text { de coleta }\end{array}$ & Rede & $\begin{array}{l}\text { Malha } \\
(\mu \mathrm{m})\end{array}$ & $\begin{array}{l}N^{\circ} \text {. de } \\
\text { inds. }\end{array}$ \\
\hline 1371 & $22^{\circ} 08^{\prime} 52,5^{\prime \prime}$ & $039^{\circ} 46^{\prime} 27,9^{\prime \prime}$ & $12 / 05 / 2002$ & oblíquo & até a termoclina & bongô & 330 & 1 \\
\hline 1300 & $2^{\circ} 02^{\prime} 30,0^{\prime \prime}$ & $039^{\circ} 49^{\prime} 41,2^{\prime \prime}$ & $12 / 05 / 2002$ & oblíquo & até a termoclina & bongô & 500 & 1 \\
\hline 565 & $22^{\circ} 32^{\prime} 03,0^{\prime \prime}$ & $040^{\circ} 17^{\prime} 21,0^{\prime \prime}$ & $19 / 05 / 2002$ & oblíquo & $30 \mathrm{~m}$ & bongô & 330 & 1 \\
\hline 628 & $22^{\circ} 42^{\prime} 06,0^{\prime \prime}$ & $040^{\circ} 14^{\prime} 26,0^{\prime \prime}$ & $19 / 05 / 2002$ & oblíquo & $50 \mathrm{~m}$ & bongô & 330 & 3 \\
\hline 570 & $22^{\circ} 32^{\prime} 03,0^{\prime \prime}$ & $040^{\circ} 17^{\prime} 21,0^{\prime \prime}$ & $19 / 05 / 2002$ & oblíquo & $30 \mathrm{~m}$ & bongô & 500 & 1 \\
\hline 462 & $22^{\circ} 33^{\prime} 47,7^{\prime \prime}$ & $040^{\circ} 12^{\prime} 20,5^{\prime \prime}$ & $17 / 05 / 2002$ & oblíquo & $50 \mathrm{~m}$ & bongô & 500 & 2 \\
\hline 631 & $22^{\circ} 42^{\prime} 06,0^{\prime \prime}$ & $040^{\circ} 14^{\prime} 26,0^{\prime \prime}$ & $19 / 05 / 2002$ & oblíquo & $50 \mathrm{~m}$ & bongô & 500 & 2 \\
\hline 623 & $22^{\circ} 36^{\prime} 54,9^{\prime \prime}$ & $09 ' 19,4 "$ & $16 / 05 / 2002$ & oblíquo & 50 & bongô & 500 & 3 \\
\hline 22186 & $22^{\circ} 34^{\prime} 05,0^{\prime \prime}$ & 19'40,0" & $17 / 05 / 2002$ & oblíquo & $600 \mathrm{~m}$ & cilíndrico-cônica & 500 & 1 \\
\hline 692 & 7'35,5" & 9'32,8" & $16 / 05 / 2002$ & oblíquo & $1.000 \mathrm{~m}$ & cilíndrico-cônica & 500 & 1 \\
\hline 7503 & $21^{\circ} 58^{\prime} 31,0^{\prime \prime}$ & $039^{\circ} 50^{\prime 29,7 "}$ & $10 / 10 / 2001$ & oblíquo & $1.000 \mathrm{~m}$ & cilíndrico-cônica & 500 & 2 \\
\hline 22184 & $22^{\circ} 02^{\prime} 35,2^{\prime \prime}$ & $039^{\circ} 43^{\prime} 18,2^{\prime \prime}$ & $04 / 12 / 2002$ & vertical & $700-1.200 m$ & cilíndrico-cônica & 500 & 1 \\
\hline 22182 & $22^{\circ} 39,68^{\prime}$ & $040^{\circ} 03,24^{\prime}$ & $13 / 06 / 2003$ & vertical & $500-1.000 m$ & cilíndrico-cônica & 500 & 1 \\
\hline
\end{tabular}

Referências: Moser et al., 1977; Anderson, 2003; Anderson \& Springer, 2005; Hardy, $2006 a$. 


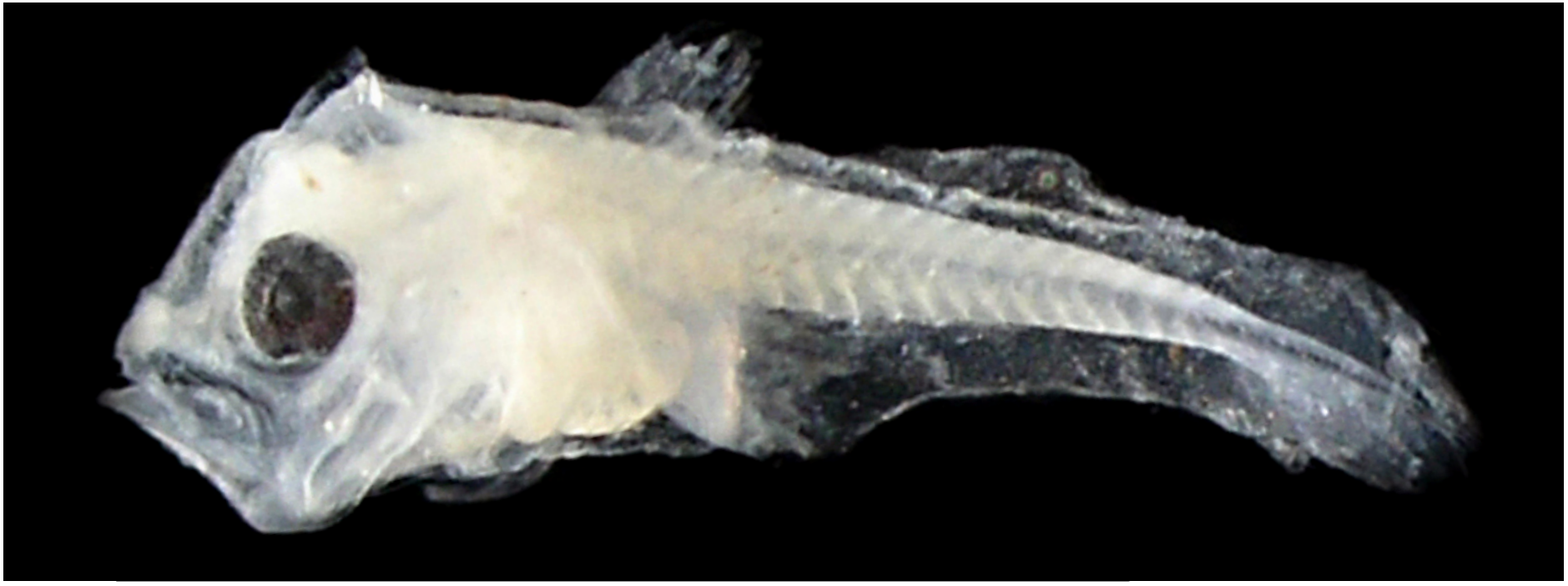

Figura 102 - A: Scorpaenodes sp. DZUFRJ 19364; Pré-flexão; CP 2,7 mm.

\section{Scorpaenodes sp.}

Em Scorpaenodes os espinhos da cabeça estão presentes em larvas em pré-flexão (<3,0 mm). As nadadeiras peitorais são grandes desde a pré-flexão e alcançam a metade das nadadeiras dorsal e anal. A pigmentação das nadadeiras peitorais é limitada à margem distal. Durante a pré-flexão, nas larvas recém eclodidas, há uma série de aproximadamente 12 melanóforos ao longo da linha média ventral da cauda. Estes se tornam internos e não são mais visíveis em larvas em flexão (> 4,0 mm). A flexão da notocorda ocorre entre 4,0 e 5,0 mm. Na pós-flexão possuem uma crista parietal bifurcada posteriormente, com um espinho nucal posterior grande. Não apresentam a capa de melanóforos que recobre a superfície dorso-lateral do intestino. Há uma mancha interna profunda na região dorso-posterior da base da nadadeira peitoral, que aumenta e cobre a superfície dorsal da vesícula gasosa. As larvas de Scorpaenodes diferem das demais, exceto Sebastobolus, por possuírem cristas

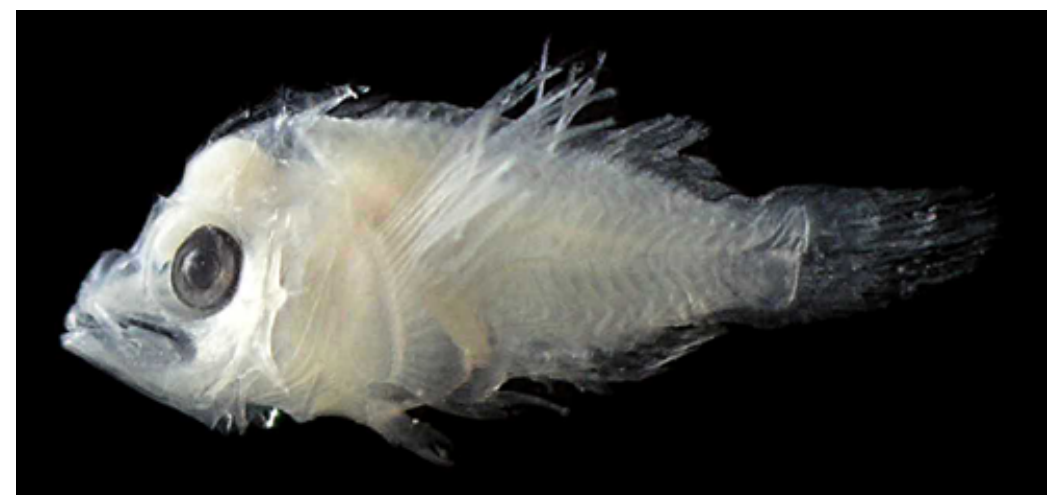

Figura 102 - B: DZUFRJ 11985; Flexão; CP 4,3 mm.

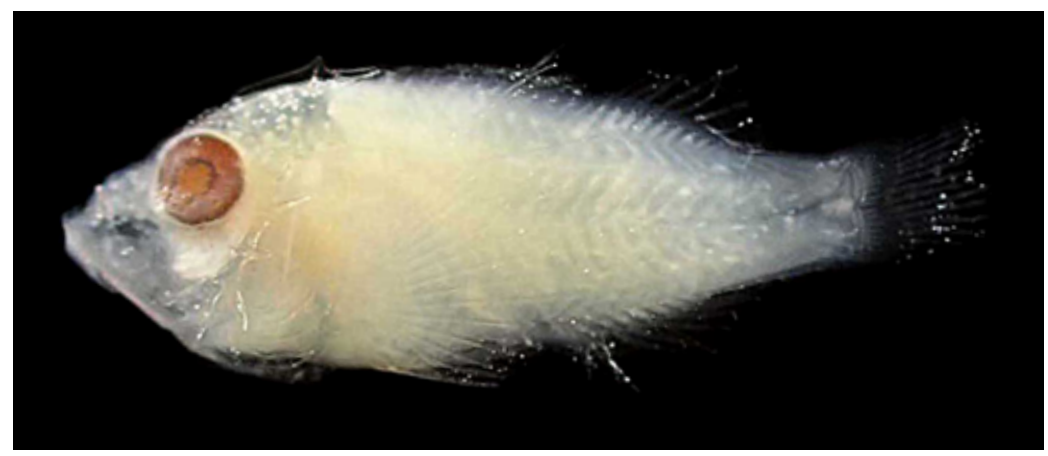

Figura 102 - C: DZUFRJ 19365; Pós-flexão; CP 9,0 mm. parietais proeminentes que terminam em espinhos duplos; o posterior (nucal) é mais proeminente do que o anterior (parietal). Os espinhos da cabeça e do corpo se desenvolvem em tamanhos menores em Scorpaenodes quando comparado a Sebastobolus. O número total de miômeros varia entre 24 e 25.

Tamanho: pré-flexão 2,7-3,0 mm; flexão 4,0-5,0 mm; pós-flexão 5,5-9,0 mm.

Habitat: todas as espécies de Scorpaenodes são marinhas e demersais. No Brasil já foram registradas as espécies Scorpaenodes caribbaeus Meek \& Hildebrand, 1928 e Scorpaenodes tredecimspinosus Metzelaar, 1919. 


\section{Georreferencimento}

\begin{tabular}{|c|c|c|c|c|c|c|c|c|}
\hline DZUFRJ & Latitude (S) & Longitude (W) & Data & $\begin{array}{l}\text { Tipo de } \\
\text { arrasto }\end{array}$ & $\begin{array}{c}\text { Profundidade } \\
\text { de coleta }\end{array}$ & Rede & $\begin{array}{l}\text { Malha } \\
(\mu \mathrm{m})\end{array}$ & $\begin{array}{l}N^{\circ} \text {. de } \\
\text { inds. }\end{array}$ \\
\hline 662 & $22^{\circ} 38^{\prime} 25,0^{\prime \prime}$ & $040^{\circ} 17^{\prime} 41^{\prime \prime}$ & $19 / 05 / 2002$ & oblíquo & $40 \mathrm{~m}$ & bongô & 330 & 1 \\
\hline 539 & $22^{\circ} 34^{\prime} 05,0^{\prime \prime}$ & 040¹9'40" & $17 / 05 / 2002$ & oblíquo & $600 \mathrm{~m}$ & cilíndrico-cônica & 500 & 2 \\
\hline 7525 & $21^{\circ} 57^{\prime} 10,5^{\prime \prime}$ & $039^{\circ} 43^{\prime} 33,3^{\prime \prime}$ & 09/10/2001 & oblíquo & $1.000 \mathrm{~m}$ & cilíndrico-cônica & 500 & 1 \\
\hline 7504 & $21^{\circ} 53^{\prime} 10,4^{\prime \prime}$ & $039^{\circ} 45^{\prime} 49,9^{\prime \prime}$ & $10 / 10 / 2001$ & oblíquo & $1.000 \mathrm{~m}$ & cilíndrico-cônica & 500 & 1 \\
\hline 7523 & $21^{\circ} 58^{\prime} 31,0^{\prime \prime}$ & $039^{\circ} 50^{\prime} 29,7^{\prime \prime}$ & $10 / 10 / 2001$ & oblíquo & $1.000 \mathrm{~m}$ & cilíndrico-cônica & 500 & 1 \\
\hline 7524 & $21^{\circ} 58 ' 31,0^{\prime \prime}$ & $039^{\circ} 50^{\prime} 29,7^{\prime \prime}$ & $10 / 10 / 2001$ & oblíquo & $1.000 \mathrm{~m}$ & cilíndrico-cônica & 500 & 1 \\
\hline 22183 & $22^{\circ} 32^{\prime} 50,0^{\prime \prime}$ & $040^{\circ} 04^{\prime} 09,9^{\prime \prime}$ & $06 / 11 / 2001$ & oblíquo & $1.000 \mathrm{~m}$ & cilíndrico-cônica & 500 & 1 \\
\hline 19365 & $22^{\circ} 31^{\prime} 58,9^{\prime \prime}$ & $040^{\circ} 02^{\prime} 53,4^{\prime \prime}$ & $07 / 11 / 2001$ & oblíquo & $1.000 \mathrm{~m}$ & cilíndrico-cônica & 500 & 1 \\
\hline
\end{tabular}

Referências: Moser et al., 1977; Hardy, $2006 a$. 